\title{
Towards an International Tissue Engineering Curriculum: The Drexel Initiative
}

\author{
Cato T. Laurencin, M.D., Ph.D.*०, Mohamed Attawia, M.D. , Dhirendra \\ Katti, Ph.D. ', Yusuf Khan, M.S. ${ }^{*}$, Michele Marcolongo, Ph.D. ${ }^{+}$, Frank Ko, \\ Ph.D. ${ }^{+}$, Wei Sun, Ph.D. ${ }^{\dagger}$ \\ *Department of Chemical Engineering $/{ }^{+}$Department of Materials Engineering/ \\ ${ }^{\dagger}$ Department of Mechanical Engineering, Drexel University, Philadelphia, PA
}

\begin{abstract}
As many as twenty million patients per year suffer from various organ and tissue related maladies including burns, skin ulcers, diabetes, bone, cartilage, and connective tissue defects and diseases. The financial cost to care for these patients has been estimated at as much as $\$ 400$ billion annually. Tissue engineering has emerged within the past 10 years as one possible solution to the current state of organ and tissue damage seen in Americans. However several limitations to its success still exist. Toward this issue and the emerging interest of Tissue Engineering in general, an undergraduate/graduate curriculum has been developed that embraces the strengths of relevant disciplines from both the sciences and Engineering to train future engineers to tackle the interdisciplinary issues surrounding the regeneration and repair of tissues. Centered around a three-year structure, the curriculum is initially designed to provide an area of concentration for upper-class undergraduate and graduate students pursuing degrees in Biomedical Science and Biomedical Engineering, but in the future could expand to encompass a full degree-awarding curriculum. In addition to class-based instruction, web-based and intercollegiate courses are suggested.
\end{abstract}

\section{Introduction}

Each year many Americans experience organ and tissue damage from birth defects, disease, and accidents. As many as twenty million patients per year suffer from various organ and tissue related maladies including burns, skin ulcers, diabetes, bone, cartilage, and connective tissue defects and diseases ${ }^{1}$. The financial cost to care for these patients has been estimated at as much as $\$ 400$ billion annually ${ }^{2}$. Although there has been considerable success with organ transplants, there is the ongoing problem of biocompatibility between donor and host, and the body's natural rejection of foreign tissue ${ }^{3}$. There is also a tremendous shortage of organs with as many as 50,000 people on transplant waiting lists in the United States ${ }^{1}$. There has been limited success with autografts. However the donor tissue is not always available or biologically appropriate for the new application, as in the case of using the saphenous vein to perform a coronary bypass ${ }^{4}$. There is no problem with host rejection, but the compliance and musculature of a vein are not an ideal replacement for a coronary artery. Considering the above necessity for and limitations of conventional organ replacement schemes, a solution is necessary.

○ To whom correspondence should be addressed 
Tissue engineering has emerged within the past 10 years as one possible solution to the limitations described above $\mathrm{s}^{5}$. A matrix or scaffold composed of natural, synthetic, or composite materials is designed to mimic the three-dimensional structure of organs and tissues. These matrices are combined with living cells that can either be seeded onto the matrix in vitro and then implanted in vivo, or interact with the matrix in vivo. However, these matrices can also serve as drug or factor delivery vehicles, providing site-specific delivery of growth factors after implantation. In addition tissue engineering includes the use of cell systems alone. Stem cells, or cells that have not fully differentiated, can be placed into a site and form new tissue given the appropriate biological stimuli.. One of the strengths of tissue engineering is that it encompasses several engineering and science disciplines. The construction of matrices borrows knowledge from mechanical engineering, material science, polymer science, and chemical engineering, while the cellular interaction incorporates cell biology, biochemistry, and molecular biology ${ }^{1}$. Combining the interaction of these fields with the clinical environment provides a body of knowledge that encompasses every aspect of the field.

Although many advances have been made over the past ten years in Tissue Engineering, several hurdles still exist. Many questions still exist regarding the nature of the material constructs used in tissue-engineered settings. For example, it is generally accepted that for successful bone tissue engineering, a porous matrix is preferred over a nonporous one for tissue ingrowth and cellular migration. Towards this end, several matrices have been studied, but even primary questions such as the precise relationship between matrix architecture and cell growth have not been completely defined ${ }^{6}$. There are also several questions related specifically to cellular behavior within the tissue environment such as the mechanisms used in cell-cell signaling, the influence of the environment on this signaling, and the relationship between cells growing in vitro and those growing in vivo. For instance, the cell is subject to and generates several growth factors in vivo. Several studies are investigating the benefit of these growth factors to cell growth in vitro, but much work remains in defining the interaction of these growth factors and their influence on cellular growth. Although a great deal of work has been performed in the area of drug delivery, the use of such systems towards application in regenerative organ systems has not been explored fully and is an area that has great potential. There is also much work to be done in the area of modeling of scaffolds and cellular behavior. For instance, modeling the 3 dimensional structure of a matrix using CAD-CAM techniques and examining the potential chemical and mass transfer within and throughout the scaffold would allow a more refined design for future scaffolds. Modeling flow environments through computer-rendered blood vessels may provide valuable information for the design of synthetic engineered grafts.

Although training in both life science-based and engineering-based fields provides the necessary background for work in these areas, very few, if any, training programs discuss these topics in a tissue-engineering framework. That is, very few biology courses discuss the reaction of cells to particular materials, while very few fluid dynamics courses discuss the flow of blood through an artery. While many scientists and engineers have either sought additional training or have made the leap across disciplines to tackle these questions, a formalized method of training future Tissue Engineers is necessary.

We have developed and continue to build an undergraduate/graduate curriculum that embraces the strengths of relevant disciplines from both the sciences and Engineering to train future 
engineers to tackle the interdisciplinary issues surrounding the regeneration and repair of tissues. The activities under this curriculum cross all necessary science and engineering boundaries within Drexel University, encompassing departments of Chemical, Biomedical, Mechanical, and Materials engineering. The curriculum also utilizes the world wide web to provide a web-based curriculum. Specifically designed to permit site-independent dual degrees between Drexel University and other local colleges, the web-based curriculum also presents opportunities for national and international collaborations.

\section{The Curriculum}

The curriculum is organized into six key areas including advanced biomaterials, cell-tissue construct interaction, protein factor technology, scaffold design and manufacturing, biosurfaces, and computer-aided tissue engineering. This structure was built on the original curriculum developed in 1999, which encompassed seven courses to be taken over three years (see Table 1). Drexel University's academic calendar is divided into quarters, which allows for the completion of more than two courses per academic year. At this juncture, the courses do not lead to a formal degree in Tissue Engineering, but provide the opportunity for a concentration in this novel area of study. For instance, the Advanced Biomaterials and the Tissue Engineering courses are part of a Biomaterials focus for both undergraduate and graduate students pursuing either Biomedical Science or Biomedical Engineering degrees. The long-term plan is to expand the curriculum to the point where undergraduates can receive a BS and graduate students can receive either an MS or $\mathrm{PhD}$ in Tissue Engineering.

\begin{tabular}{|c|c|c|c|}
\hline Curriculum Year & Fall Quarter & Winter Quarter & Spring Quarter \\
\hline Year One & $\begin{array}{c}\text { BMES 661 } \\
\text { Advanced Biomaterials }\end{array}$ & $\begin{array}{c}\text { BMES 662 } \\
\text { Tissue Engineering }\end{array}$ & No Course \\
\hline Year Two & No Course & $\begin{array}{c}\text { BMES 506 } \\
\text { Computer Aided Tissue } \\
\text { Engineering }\end{array}$ & $\begin{array}{c}\text { BMES 663 } \\
\text { Advanced Cell Biology in } \\
\text { Tissue Engineering }\end{array}$ \\
\hline Year Three & $\begin{array}{c}\text { BMES 504 } \\
\text { Factor Mediated Tissue } \\
\text { Engineering }\end{array}$ & $\begin{array}{c}\text { CAD/CAM for Tissue } \\
\text { Engineering }\end{array}$ & $\begin{array}{c}\text { BMES 505 } \\
\text { Biosurfaces }\end{array}$ \\
\hline
\end{tabular}

Table 1. Curriculum breakdown by course and year.

\section{Year One}

In the fall quarter of the first year, a Case-Study based graduate level Biomaterials course was included. The first half of the course involved natural tissue properties i.e. how biological tissue works and the latter half emphasized on biomaterials. The student population, as in many biomedical engineering courses, come from widely different backgrounds. Therefore to effectively introduce material science and engineering to these students, a case study structure was implemented that focuses on a total hip arthroplasty.

The goal of this course is to have the students understand how the body's natural tissues are organized on a compositional, structural, and properties basis, to understand how the body deals with foreign objects placed in its realm, and to understand to the best of our knowledge how implanted materials have been successful in achieving the ultimate goal of treating debilitating 
diseases. Clearly, this course offers an introduction to the topics, realizing that each topic in and of itself could be a separate graduate course.

We had the challenge in this field of needing to comprehend and analyze several different aspects to natural and synthetic biomaterials. Some concepts covered in this course included biocompatibility, cell/surface interactions, material structure, material properties (mechanical, electrical, chemical, and surface), and materials processing. Because the study of biomaterials involves such different endeavors, it is truly a multi-disciplinary field. As such, students may come from broadly different backgrounds; therefore to be an "expert" in biomaterials, students must embrace the significance of each discipline's contribution to the use of materials in medicine. The general focus of this course is to introduce all pertinent topics regarding biomaterials, and by the end of the term to have all students on the same platform in the subject of Biomaterials.

For "Tissue Engineering" taught in the winter quarter of year one, a team teaching format was implemented. The basic elements of the subject of tissue engineering were presented by the core faculty of the Drexel University Tissue Engineering graduate program. As a part of this course selected experiments were also performed by the students as team projects to illustrate the principles of tissue engineering. The topics discussed for this course were divided into lectures and labs from associated faculty and covered the following topics; Introduction to Tissue Engineering, Scaffold development and characterization, Cell technology, isolation, and mechanics, Surface Interactions, Drug Delivery, Computer Aided scaffold design, and FactorMediated tissue engineering.

\section{Year Two}

In Year Two of the curriculum, "Introduction to Computer Aided Tissue Engineering" was introduced. This course was designed for graduate and/or senior undergraduate students in engineering and bioengineering who were interested in acquiring the knowledge and skill in using computer-aided technologies for tissue engineering applications. The course introduced:

1) the latest advances of CAD/CAM/CAE in modern design and manufacturing, as well as in the field of bio-medical and tissue engineering; 2) knowledge on computer-aided design and modeling, bioModeling, three-dimensional reconstruction, and rapid prototyping of anatomical modeling and implants; and 3) a hand-on experience on using advanced computer software and rapid prototyping system for design and modeling of tissue engineered structures. The course was conducted in joint lectures and projects/laboratories.

In the Spring quarter of Year Two, "Advanced Cell Biology in Tissue Engineering” was introduced into the Tissue Engineering curriculum. This course was offered to graduate and senior undergraduate students in engineering majors including biomedical engineering. The course was designed to give a comprehensive coverage of the cell biology aspect of Tissue Engineering. This included understanding the cell structure, cell functions and its environment i.e. extracellular matrix, cell adhesion molecules etc. Topics such as cell handling, cell growth, maintenance of cell lines, and passing of cells at confluency were covered under Cellular techniques. Cellular aspects of tissue engineering including cell transplantation and grafts, gene 
therapy, stem cell therapy and bioreactors in tissue engineering were covered in detail to enable students get a better understanding of the latest developments in tissue engineering.

As a part of the course the class conducted a visit to the Wistar Institute at the University of Pennsylvania for a hands on experience on Bioreactors and their applications in Tissue Engineering. The visit included a lecture on 'Bioreactors in Tissue Engineering' followed by a demonstration on the design, function and use of Bioreactors to help students gain a better understanding of Bioreactors and their use in Tissue Engineering. The course also involved a guest lecture by a researcher in Tissue Engineering and a practicing Board Certified, Orthopaedic Surgeon. The lecture gave the class a unique opportunity to get a clinician's views on the existing techniques in Tissue Engineering and the emerging trends in Tissue Engineering. The class had an opportunity to get the industrial perspective of Tissue Engineering. The lecture was entitled 'Stem Cell Applications in Medical and Tissue Engineering' and involved a brief outline of stem cells, their availability and isolation followed by a detailed account on the application/use of stem cells in the area of tissue regeneration and repair. This lecture gave the students a better understanding of the industrial aspects of Tissue Engineering.

\section{Year Three}

Year Three began this past fall with "Factor Mediated Tissue Engineering". This course presented a focused approach towards understanding the rationale and challenges in utilizing biological factors for tissue engineering applications. The objective of this course was to provide students with the latest review of the expression of growth factors and the analysis of their properties and the evidence of their importance in tissue engineering. The lecture topics included an overview of biological factors, specific applications of factors in bone tissue engineering, cartilage engineering, neural tissue engineering, and vascular tissue engineering, delivery of factors via drug delivery systems, and gene therapy strategies for tissue engineering.

The winter quarter offered the continuation of Year Two's "Computer Aided Tissue Engineering" while the spring quarter will offer "Biosurfaces", a graduate level course on biosurface science and engineering. The objective of this course is to educate students in the interactions between a biomaterials surface and the physiological environment by blending the fields of molecular and cell biology with surface science and engineering. We will explore the effect of specific surface properties, such as charge, chemistry, energy, and topography on the conformation and adsorption of proteins as well as the attachment and maturation of cells.

Throughout the course, each topic will be introduced using hydroxyapatite as a case study. This dynamic material offers an exciting venue to explore the surface properties that lead this material to eliciting its interesting cellular response in vivo. This will serve to give immediate example of each newly introduced concept to a material that is well-investigated. The students will uncover the mysteries of bioactivity and develop an understanding of the surface environment of hydroxyapatite as they internalize the physical concepts of molecular engineering of surface properties. 


\section{Future Directions and Objectives}

Given the highly successful initial venture, further funding is being pursued to expand the curriculum both intramurally with additional coursework, and extramurally with both web-based and community outreach programs.

\section{Additional Coursework}

With the high level of interest and success with the initial course offering, several new and expanded courses are currently being designed. For instance, the original Advanced Biomaterials is being expanded to two courses that will examine the elements of the original course but in greater detail. A new course entitled "Scaffold Design and Manufacturing" will examine in detail the design, synthesis, and characterization of several scaffolds for tissue engineering. The Factor-Based Tissue Engineering and CAD/CAM-based courses will also be expanded. New courses will be implemented in the areas of Experimental Biomechanics, Cellular Biomechanics, and Pharmaceutical Engineering to cater to the high interest levels of students from diverse engineering backgrounds.

\section{Web-Based Courses}

As the tissue engineering curriculum embraces undergraduate students from a broad range of disciplines, it may be difficult to gauge the strengths of these students until they have enrolled in courses. This is a universal challenge to regenerative/tissue engineering programs. We have proposed a common ground program that is a self-study, web-based tutorial at an introductory level. We will develop web-based course materials for topics of biomaterials, biomechanics, and cell biology that will be produced by the faculty.

Each student will be encouraged to supplement his or her background as he or she sees fit, so that the student population is prepared to some standard level of knowledge across the span of pertinent biomaterials and regenerative engineering topics. A Drexel graduate student will be recruited as the course web-master. To complement the tutorial, weekly sessions will be held for each topic for the first term of the academic year. This way, students will be able to ask questions and interact with a faculty member on a weekly basis to facilitate the self-study. Consequently, a basic level of engineering knowledge can be assumed for the student population and coursework can be directed to that level of understanding. This will likely lead to a higher level of study in the classroom and a higher degree of confidence for the student entering this new field.

\section{Community Outreach}

One of the major focuses of this program is to expose underrepresented minorities to opportunities in science and engineering. One particularly exciting area today and in the future is the area of Biomaterials Science and Engineering. In this project, we will develop a one-week summer enrichment course in Biomaterials Science and Engineering for inner-city high school students to be held at Drexel University. As the Philadelphia public school district serves a population that is roughly $76 \%$ underrepresented minorities (64\% African-American, 12\% 
Latino), a majority of the applicants will be from these groups. The course will consist of 5 once-daily lectures on basic biomaterials and applications as well as daily laboratory experiments. The goal of the lectures will be to introduce the students to the field of biomaterials and to provide them with an exposure to an exciting area in the field of Bioengineering. The goal of the laboratory experiments will be to allow the high school students to get "hands-on" experience working with state of the art research instruments. The faculty will teach the course with assistance from a Ph.D. student and undergraduate research assistants. Specifically, the high school students will partner with undergraduate students to form a research team during the laboratory portion of the course. This team, consisting of 2 high school students and 1 undergraduate student, will be assigned a project during the course and will present their research proposal at the end of the course. Guidance for the project will come from the participating investigators and the graduate student.

In addition to the summer enrichment course, high school students will be invited to complete a research internship at Drexel following the completion of the course. For the internship, each student will complete, with his/her team, a 40-hour project during after school hours. Due to the size of the laboratory facility and equipment constraints, the internships will be completed sequentially by the teams during the academic year following the course. Students participating in this project will receive partial support from this grant to account for their time spent in the laboratory. Following completion of the projects, all of the teams will be required to write up a report and give an oral presentation of their projects at a wrap-up meeting. Additionally, each team will be encouraged to present a poster containing their work at the Drexel University research day in May of the year following their internship.

\section{Extramural/International Reach of the Curriculum}

The curriculum that has been developed was designed to incorporate the necessary aspects of many fields and provide a comprehensive education for future tissue engineers. We believe that this new and innovative program in Tissue Engineering research may become a national model for interdisciplinary teaching in the field. Many of the co-authors of the curriculum serve as advisors to NSF sponsored centers for engineering research and education and/or departmental visiting committee members at schools with significant NSF funding. Through formal and informal presentations, the curriculum will be described and discussed. We believe the impact of our proposed program will be high and far reaching.

The incorporation of web-based instruction has afforded us the opportunity to expand the reach of the curriculum not only beyond the University but to the international scale as well. It is our vision that the web-based curriculum may someday be used to educate students in other countries as well as other cities and universities. The Center for Advanced Biomaterials and Tissue Engineering has formed strong collaborative ties with the National Research Center in Cairo, Egypt and is currently involved in a student/faculty exchange program in which students and faculty from both Drexel University and the University of Cairo travel to their counterpart institutions to work on a joint research project. This project may form the basis for a future webbased tutorial or seminar series. The dissemination of the curriculum should not be far behind. Further, the curriculum will be enriched by the inclusion of international scholars contributing to 
its content. This ambitious effort will provide a standard by which other future programs can form.

\section{Conclusion}

Tissue engineering holds great promise for the treatment of many ailments. However its interdisciplinary nature has demanded well-trained scientists and engineers to maintain the field's exponential growth. The most appropriate way to ensure the proper training of these future engineers is through a curriculum with the specifics of the field at the core of its design. We have outlined above our vision of this curriculum as well as its potential for expansion and international influence. Drexel University is an ideal place for its growth, being in Philadelphia with its abundance of high-caliber academic institutions, being a city campus well-situated to serve the community in which it resides, and being a well-respected and academically strong engineering research institution. The initial success of the curriculum has paved the way for growth both intra- and extramurally, and has provided the grounds for international collaboration, both on a research and curriculum-based level.

\section{References}

1. Lanza RP, Langer R, Vacanti JP. Principles of Tissue Engineering. $1^{\text {st }}$ Ed., Academic Press, San Diego, 1997.

2. Patrick Jr. CW, Mikos AG, McIntire LV. Frontiers in Tissue Engineering. Pergamon, New York, 1998.

3. Tomford, WW. Transmission of Disease through Transplantation of Musculoskeletal Allografts. J Bone Joint Surg. 77-A(11), 1742-1754, 1995.

4. Ratcliffe A. Tissue Engineering of Vascular Grafts. Matrix Biology. 19, 353-357, 2000.

5. Langer R, Vacanti JP. Tissue Engineering. Science. 260(5110), 920-926, 1993.

6. Agrawal CM, Ray RB. Biodegradable polymeric scaffolds for musculoskeletal tissue engineering. J Biomed Mater Res. 55, 141-150, 2001.

\section{Biographical Information}

\section{Dr. Cato T. Laurencin}

Education: 1987, M.D. degree (Magna Cum Laude) Harvard Medical School, Boston MA, 1987, Ph.D. degree Biochemical Engineering/Biotechnology, Massachusetts Institute of Technology, Cambridge, MA, 1980 B.S.E. degree, Chemical Engineering, Princeton University, Princeton, NJ.

Current title: Helen I. Moorehead Distinguished Professor of Chemical Engineering Drexel University, Philadelphia, PA

Clinical Professor of Orthopaedic Surgery MCP-Hahnemann School of Medicine Professor of Pharmacology and Physiology MCP/Hahnemann School of Medicine 


\section{Dr. Mohamed Attawia}

Education : 1978: M.B.B.Ch., Cairo Medical School, Cairo, Egypt.

Professional Experience: 1994-1998, Research Assistant Professor (Department of Orthopaedics): Allegheny University Hospital. Philadelphia PA 1998-2001, Research Associate Professor (Department of Chemical Engineering), Drexel University 2001-Present Orthobiologics, DepuyAcromed, Johnson \& Johnson Company.

\section{Dr. Dhirendra S. Katti}

Education: 1999, Doctor of Philosophy (Ph.D.), Chemistry, Bombay University. 1993, Bachelor of Science in Technology (B.Sc. Tech.), Chemical Technology, Bombay University. 1990, Bachelor of Science (B.Sc.), Chemistry, Poona University.

Professional Experience: December 2001-Present, Research Assistant Professor, Drexel University. 1999-2001, Post Doctoral Fellow, Drexel University.

\section{Mr. Yusuf Khan}

Education: MS in Biomedical Engineering from Drexel University 1999. Currently pursuing $\mathrm{PhD}$ in Biomedical Engineering from Drexel University. Anticipated date of graduation, 2003.

\section{Dr. Michele Marcolongo}

Education: University of Delaware 1986, Bachelor of Science in Mechanical Engineering; Drexel University 1989, Masters degree in Mechanical Engineering; University of Pennsylvania 1992, Masters degree in Bioengineering; University of Pennsylvania 1995 Ph.D. in Bioengineering.

Professional Experience: 1994 - 1997 Depuy Dupont Orthopaedics, Research Engineer 1997-present, Drexel University, Assistant Professor Departments of Materials and Biomedical Engineering

\section{Dr. Frank Ko}

Director of the Fibrous Materials Research Center and Professor of Materials Engineering at Drexel University. He received his B.S. degree from Philadelphia College of Textiles and Science. He holds an M.S. and a Ph.D. degree in Textile Engineering from the Georgia Institute of Technology. A SAMPE Fellow and recipient of the Drexel Research award and the Fiber Society Award for Distinguished Achievement, Professor Ko has published and presented over 300 papers in the subject of engineering properties and technology of fibrous materials and in their biomedical, industrial and composite applications.

\section{Dr. Wei Sun}

Education: Ph.D., 1992, Mechanical Engineering, Drexel University

Professional Experience: 1998-Present, P.C. Chou Assistant Professor, Mechanical Engineering, Drexel University 1994-Present, Director, Rapid Product Development Center, Drexel University; Research interests: CAD/CAM, Computer-Aided Tissue Engineering, Solid Freeform Fabrication 